Revista Destaques Acadêmicos, Lajeado, v. 8, n. 4, 2016. ISSN 2176-3070 DOI: http://dx.doi.org/10.22410/issn.2176-3070.v8i4a2016.1199 www.univates.br/revistas

\title{
USABILIDADE EM APLICAÇÕES WEB: PROPOSTA PARA O SISTEMA DE BIBLIOTECA DA UNIVATES
}

\author{
Eduardo Bonfadini' ${ }^{1}$, Fabrício Pretto ${ }^{2}$
}

Resumo: A usabilidade está cada vez mais em pauta no contexto de desenvolvimento de software. As suas heurísticas auxiliam empresas e desenvolvedores a entregar melhores produtos, orientando os usuários na utilização dos aplicativos com facilidade e satisfação. Interfaces humano-computador não estão mais limitadas a computadores de mesa, atualmente existe uma grande série de dispositivos diferentes, móveis ou não, e suas interfaces necessitam de um estudo da relação entre máquina e computador. Neste sentido, este trabalho propôs uma nova interface para a área pública do sistema Gnuteca, ou seja, área utilizada por alunos e comunidade, não envolvendo a área administrativa do sistema de biblioteca da Univates. Objetivou-se repensar as suas telas de pesquisa de materiais, renovação e reserva, com base nos princípios de usabilidade recomendados por diversos autores e pesquisadores. Após as telas serem repensadas e desenvolvidas foram efetuados testes de usabilidade que avaliaram a real efetividade das técnicas aplicadas.

Palavras-chave: Usabilidade. Interface Humano-Computador. Sistema web. Aplicação web. Biblioteca. Gnuteca.

\section{INTRODUÇÃO}

As aplicações web estão cada dia mais enraizadas em nossas vidas, seja por meio de ferramentas de e-mail, redes sociais, fotos, vídeos e outros. Estas funcionalidades tornaram-se parte do nosso cotidiano.

Conforme Nielsen (2010), cada vez mais as pessoas esperam aplicações melhores, quanto mais o usuário utiliza as ferramentas, mais ele aprende e menos erros ele tolera.

A usabilidade é apresentada no sentido de oferecer melhores aplicações web para os usuários, leigos ou não, auxiliando na criação de projetos que atendem as reais necessidades do usuário. A relação humano-computador é

1 Graduado em Sistemas de Informação - Univates.

2 Mestre em Ciência da Computação - Professor na Univates. 
simplificada e padronizada, utilizando de técnicas reconhecidas e praticadas há mais de 20 anos. Apesar das heurísticas não serem recentes, atualmente há uma maior preocupação na entrega de bons aplicativos, tornando a usabilidade um tema atual e necessário. Atualmente, a Internet possui milhões de usuários, o que certamente justifica a importância do estudo das heurísticas de usabilidade e suas relações com o usuário (NIELSEN, 2010).

Uma biblioteca é uma organização dinâmica, sempre em evolução, incorporando novos padrões e costumes sociais, atendendo necessidades informacionais da instituição de ensino e servindo de alicerce para avanços futuros. Neste sentido é importante que seu aplicativo de gerenciamento também esteja evoluindo, dessa forma auxiliando no processo de gestão da biblioteca (GOMES, 2012).

O estudo apresentado nesse artigo esteve direcionado a uma instituição de ensino superior do Vale do Taquari, o Centro Universitário UNIVATES. O foco do projeto foi pensar, projetar, desenvolver e avaliar uma nova proposta para o sistema utilizado pela comunidade acadêmica para acesso à sua biblioteca. Por ser um sistema de grande visibilidade e utilidade para alunos da instituição como também para ex-alunos, justifica-se a importância de oferecer um sistema de alto nível de usabilidade, ou seja, fácil utilização, intuitivo e com bom nível acessibilidade.

Como objetivos específicos, procurou-se:

- Avaliar princípios de usabilidade;

- Desenvolver protótipos de telas do sistema usando princípios de usabilidade;

- Implementar os protótipos simulando as operações realizadas pelo usuário na versão atual do aplicativo;

- Efetuar testes de usabilidade, verificando e analisando os resultados obtidos.

\section{FUNDAMENTAÇÃO TEÓRICA}

A utilização de sistemas de informação tronou-se inevitável a partir do momento em que a sociedade passou a apoiar muitos de seus processos de negócio sobre esse tipo de tecnologia, o software. A correta construção de um sistema e sua facilidade de utilização, são imprescindíveis para que usuários dos mais variados perfis consigam desempenhar suas atividades diárias de forma eficiente.

\subsection{Processo de software}

Apesar de não serem fabricados no conceito clássico, softwares são criados da mesma forma que qualquer outro produto bem-sucedido, através de etapas, utilizando um processo bem definido, adaptável e ágil, que norteie 
o desenvolvimento, conduzindo a conclusão da tarefa com alta qualidade e atendendo as necessidades de quem o utilizará. Para isso aplica-se a engenharia de software (PRESSMAN, 2011).

A engenharia de software abrange um processo, um conjunto de práticas ou métodos executados através de ferramentas e profissionais, com o objetivo de desenvolver aplicativos de alta qualidade. A engenharia de software é importante, pois, capacita estes profissionais a criar aplicativos de alta qualidade, sejam eles complexos ou simples, atendendo a prazos e requisitos (SOMMERVILLE, 2012).

Para criar um aplicativo preparado para os desafios da atualidade é importante notar algumas situações:

- Softwares estão incorporados a aspectos diários de nossas vidas, em função disso o número de interessados na aquisição de sistemas só tem crescido.

- Usuários têm ideias diferentes de qual recurso é ou não necessário para um aplicativo, de forma que é necessário fazer um dedicado esforço para entender o problema antes de projetar a solução.

- Existe uma demanda maior, por softwares mais complexos e inteligentes, em função disso, projetar tornou-se uma atividadechave.

- Pessoas e empresas dependem de softwares, sendo que uma falha pode gerar desde pequenos inconvenientes até problemas catastróficos.

- Aplicativos precisam ser ajustados, modificados, corrigidos, melhorados, em função disso, eles precisam ser passíveis de manutenção.

- As constatações acima indicam que software, em todas as suas formas e usos deve passar pelos processos de engenharia de software.

O processo de software genérico é apresentado na Figura 1. Dentre as etapas, visualiza-se o entendimento do problema, conhecido como elicitação dos requisitos; especificação e projeto do sistema; a implementação que corresponde ao desenvolver o programa utilizando ferramentas como linguagens de programação e banco de dados; testes de verificação e validação; e, por último, a manutenção que corresponde ao acompanhamento e ajustes do sistema durante a utilização pelos usuários. 
Figura 1 - Processo de software genérico

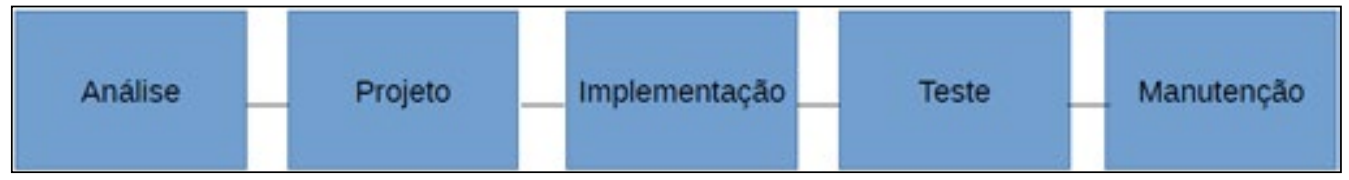

Fonte: Sommerville (2012).

\subsection{Interação Humano-Computador}

Dentre as etapas do processo de desenvolvimento de um sistema de informação, um dos momentos que merece enorme atenção por parte dos analistas e projetistas de sistemas, diz respeito ao projeto da interface da aplicação. Sistemas para computador, tais como: sites, blogs ou aplicativos móveis, seja qual for sua categoria, são manuseados por pessoas, cujas características são distintas, provocando percepções e interações diferenciadas.

Denomina-se usabilidade, como a qualidade que caracteriza o uso dos programas e aplicações, ou seja, a capacidade que um software possui de ser usável, ou o quanto ele é fácil de usar. Apesar de ser possível construir sistemas com pouca ou sem nenhuma usabilidade, ela é vista como uma qualidade essencial para um sistema ou aplicação (CYBIS, 2010).

Segundo Krug (2008) usabilidade significa certificar-se que algo funciona bem. Este mesmo autor afirma que usabilidade não é complicada e que pode ser construída por qualquer pessoa que possua alguma experiência, habilidade, bom senso e boa vontade. Ele ainda comenta que o usuário não quer pensar, que o mesmo espera conseguir utilizar o sistema com o mínimo de esforço. Quanto menor o esforço, maior a satisfação.

A usabilidade de um sistema não é algo quantificável, mas qualitativo, pois depende de uma série de fatores. Ela é uma combinação entre as interfaces do sistema, bem como a capacidade de seus usuários buscarem determinados objetivos para determinadas tarefas (PRESSMAN, 2011).

A mesma tela de um aplicativo pode causar sensações distintas para diferentes usuários. Exemplificando: uma interface pode proporcionar bom uso para usuários experientes e prejudicar o uso quando utilizada por usuários leigos. Ainda assim, estes não são os únicos fatores que afetam a usabilidade. Problemas de usabilidade podem ocorrer independentemente do tipo de usuário, como no caso da execução em computadores rápidos ou lentos bem como na periodicidade que a tarefa seja realizada (CYBIS, 2010).

No contexto da usabilidade web, o dispositivo utilizado pode impactar diretamente na sensação de satisfação por parte do usuário. Mesmo que a aplicação funcione em dispositivos com suporte a toque, não existe garantia 
alguma de que seja prático de usar nestes dispositivos, principalmente quando a aplicação não foi especialmente projetada para eles (NIELSEN, 2010).

Para construir interfaces realmente usáveis é necessário, entre outras coisas, conhecer muito bem o público-alvo do sistema, bem como as tarefas que este usuário executará. Os sistemas e suas interfaces devem ser ferramentas cognitivas, que facilitem a percepção, raciocínio, memorização e tomada de decisões. Para produzir boas interfaces é necessário que o projetista conheça as estruturas das tarefas a serem realizadas, assim como seus processos (CYBIS, 2010). Isto é um desafio, pois os usuários em sua grande diversidade criam estratégias e contextos variados para resolução das tarefas. Além do mais, as estratégias evoluem de acordo com o uso e conhecimento do sistema. Junto com essas novas estratégias criam-se novas demandas. Assim, a Interação Humano-Computador (IHC), do inglês Human-Computer Interaction (HCI) deve ser pensada como um processo em constante evolução, fazendo parte do dia a dia dos desenvolvedores e analistas de softwares (PRESSMAN, 2011).

Entretanto, para conceber algo que seja fácil de usar em situações tão diversas e adversas, serão necessários recursos especializados e o envolvimento com o usuário. É evidente que a construção de interfaces usáveis exige mais tempo e dinheiro, porém, segundo Nielsen (2010), o retorno obtido é extremamente lucrativo. Pensar melhores interfaces reduz as dúvidas do usuário, e por fim o retrabalho nestas mesmas interfaces é menor, resultando em um custo menor a médio e longo prazo.

Os usuários se sentem satisfeitos e confiantes pelas facilidades que encontram durante o aprendizado de um novo sistema que lhe permita concluir suas tarefas com menos esforço, em menos tempo e com menos erros. As empresas recebem a recompensa de seus investimentos em ergonomia e usabilidade de diversas formas: através do aumento de produtividade e vendas, diminuição de tempo e custos de treinamento, bem como da estrutura de suporte, resultando na melhoria de sua imagem perante seus clientes (NIELSEN, 2010).

\subsection{Aplicações web versus aplicações desktop versus páginas}

Este trabalho visa abordar um tipo específico de aplicação, a aplicação web. Tecnicamente uma aplicação web não difere muito de uma aplicação desktop tradicional (FOWLER, 2010).

Aplicações web podem mostrar informações de formas mais variadas e ricas, em comparação a uma aplicação desktop. Um exemplo: um diagrama com os computadores de uma rede pode demonstrar um servidor inacessível, e caso necessário, reiniciá-lo somente clicando no seu ícone. Aplicações web podem ser mais coloridas e com visual mais atraente que a maioria das aplicações desktop (PRESSMAN, 2011). 
Por outro lado, controles Hypertext Markup Language (HTML) não são completos o suficiente; botões e outros elementos são muito simples, eles não possuem a flexibilidade das suas contrapartes como os sistemas operacionais Windows, Linux ou Mac. Nos casos em que são flexíveis existe uma grande possibilidade de que sua funcionalidade irá parar de funcionar em certos navegadores ou versões diferentes de um mesmo navegador.

As incompatibilidades entre navegadores são contra produtivas, algumas vezes chegando ao ponto de impedir a criação de componentes de interação personalizados. Os processos não acontecem do mesmo jeito em navegadores diferentes, os desenvolvedores algumas vezes, são forçados a criar soluções para o denominador comum mais baixo (PRESSMAN, 2011).

No entanto, nas aplicações web existem compensações. Os botões de voltar e avançar são uma das ideias mais poderosas em décadas. O conceito de página inicial "home" também é muito interessante. Uma tarefa que inicie na tela inicial, execute o seu processo por diferentes páginas e termine novamente na página inicial gera uma grande sensação de conclusão de tarefa e satisfação ao usuário (FOWLER, 2010).

Aplicações entregues via navegador não precisam ser instaladas em cada computador. Para grandes corporações, com centenas de funcionários, instalar ou atualizar aplicações desktop pode gerar uma série de problemas, bem como custos elevados (PRESSMAN, 2011).

Acessíveis pela internet, por meio dos navegadores, estão também em grande número, as páginas web. A maioria dessas páginas web possui diversas pequenas aplicações incluídas dentro dela. Como exemplo de pequena aplicação é possível citar o site <http:/ /globo.com>, que possui um sistema de busca textual dentro de um site de conteúdo. O exemplo está relacionado com a ideia de que uma página web pode conter diversas pequenas aplicações, sem necessariamente ser uma aplicação web.

De forma geral, uma aplicação web é algo com o qual o usuário interage, onde é possível ler e gravar informações. Para que exista uma aplicação web é necessário existir o conceito de persistência, normalmente relacionado com a camada do banco de dados. Por outro lado, páginas normalmente só mostram informações. Entretanto, aplicações web e páginas web são muito similares, pois a tecnologia de construção é a mesma, de fato ambas possuem apelo visual, logotipos, informações corporativas e conteúdo rico (FOWLER, 2010).

Portanto, a chave para este questionamento, o que realmente difere uma aplicação web de uma página, são as expectativas e propósitos do usuário. De acordo com os propósitos da aplicação ou página serão escolhidos os padrões de interface a serem seguidos (FOWLER, 2010). 


\subsection{Boas práticas de usabilidade}

Definidas por Nilsen (1994), Cybis (2010) e Pressman (2011), a Tabela 1 apresenta um conjunto de boas práticas que seguem as recomendações feitas quanto ao projeto de interfaces e qualidade de usabilidade.

Tabela 1 - Conjunto de boas práticas

\begin{tabular}{|c|c|}
\hline Recomendação & Significado \\
\hline Diálogo simples e natural & $\begin{array}{l}\text { A interface com o usuário deve ser simplificada o quanto for } \\
\text { possível, sendo que cada funcionalidade ou tela adicional é } \\
\text { algo a mais para o usuário aprender. } \\
\text { Ex. Um busca na internet. O mecanismo de busca Google } \\
\text { possui em evidência no centro de sua tela um enorme } \\
\text { campo para consulta. }\end{array}$ \\
\hline Princípio da condução & $\begin{array}{l}\text { Qualidade de uma aplicação de favorecer o aprendizado, } \\
\text { a compreensão e a sua utilização pelo usuário, englobando } \\
\text { os meios utilizados para levar o usuário a realizar } \\
\text { determinadas ações. } \\
\text { Ex.: Opções de clique e digitação visíveis. Menus de } \\
\text { navegação simples, permitindo ao usuário perceber o que } \\
\text { pode realizar. }\end{array}$ \\
\hline $\begin{array}{l}\text { Princípio ergonômico de } \\
\text { convite, agrupamento } \\
\text { e distinção entre itens e } \\
\text { legibilidade }\end{array}$ & $\begin{array}{l}\text { Separar e aproximar itens e grupos nas telas conforme as } \\
\text { relações lógicas que se estabelecem entre eles, bem como } \\
\text { efetuar a distinção visual entre áreas abrigando elementos } \\
\text { de funções diferentes (comandos, ferramentas, dados, } \\
\text { informações). } \\
\text { Ex.: Agrupamentos de funções, campos de entrada de } \\
\text { dados, critérios de busca. Distinção pode cor e formato } \\
\text { (negrito, itálico ou sublinhado). }\end{array}$ \\
\hline $\begin{array}{l}\text { Uma interface não deve } \\
\text { parecer poluída }\end{array}$ & $\begin{array}{l}\text { Pequeno grupo de cores consistentes, que deveriam estar } \\
\text { limitadas de } 5 \text { a } 7 \text { cores. }\end{array}$ \\
\hline $\begin{array}{l}\text { A interface deve poder } \\
\text { ser usada sem cores }\end{array}$ & $\begin{array}{l}\text { Importante registrar que } 8 \% \text { das pessoas são daltônicas, } \\
\text { então é necessário que a interface possa ser compreendida } \\
\text { mesmo sem as informações de cor. }\end{array}$ \\
\hline Uso adequado de cores & $\begin{array}{l}\text { Utilizar cores somente para categorizar, diferenciar e } \\
\text { destacar. Cores não devem ser usadas para entrega de } \\
\text { informação. }\end{array}$ \\
\hline Menos é mais & $\begin{array}{l}\text { Garantir que o usuário irá atingir o seu objetivo. É melhor } \\
\text { criar uma tela simples com estas informações e deixar o } \\
\text { resto para outras telas auxiliares, em vez de criar uma } \\
\text { tela cheia de campos e informações que acabam sendo } \\
\text { prejudicial à compreensão por parte do usuário. }\end{array}$ \\
\hline
\end{tabular}




\begin{tabular}{l|l}
\hline Recomendação & Significado \\
\hline Falar a língua do usuário & $\begin{array}{l}\text { Fornecer interfaces baseadas no idioma do usuário e não em } \\
\text { termos orientados ao sistema. Refere-se ao idioma falado } \\
\text { (português, inglês, ...), como também termos técnicos e } \\
\text { regionalistas e da área de negócio. Ex. símbolo monetário } \\
\text { no Brasil é representado por R\$. }\end{array}$ \\
\hline Minimizar o esforço & $\begin{array}{l}\text { Relacionado a carga informacional. De modo geral, é muito } \\
\text { mais fácil para as pessoas reconhecer alguma coisa quando } \\
\text { ela é visualizada do que quando é necessário buscá-la da } \\
\text { memória. } \\
\text { Ex.: Possibilitar escolhas ao invés de digitação. }\end{array}$ \\
\hline Consistência e padrões & $\begin{array}{l}\text { Princípio básico de usabilidade. A mesma informação deve } \\
\text { ser apresentada no mesmo local em todas as telas, caixas } \\
\text { de diálogos devem ser formatadas da mesma forma para } \\
\text { facilidade de compreensão. Homogeneidade e a coerência } \\
\text { são palavras-chave. }\end{array}$ \\
\hline $\begin{array}{l}\text { Feedback - retorno ao } \\
\text { usuário }\end{array}$ & $\begin{array}{l}\text { Continuadamente informar o usuário sobre o que está } \\
\text { fazendo e como está interpretando suas entradas de } \\
\text { informações. O retorno não deve somente ser um erro, o } \\
\text { sistema também deve dar retorno positivo, e deve também } \\
\text { informar retorno parcial quando possível. }\end{array}$ \\
\hline
\end{tabular}

Fonte: Nilsen (1994), Cybis (2010) e Pressman (2011).

A Figura 2 apresenta o exemplo de uma interface de aplicação web contendo informações visuais organizadas da seguinte forma:

1. Menu principal da aplicação

2. Título da página

3. Campos para preenchimento do usuário

4. Campos específicos para endereço

5. Ações para esta página 
Figura 2 - Exemplo de distinção visual

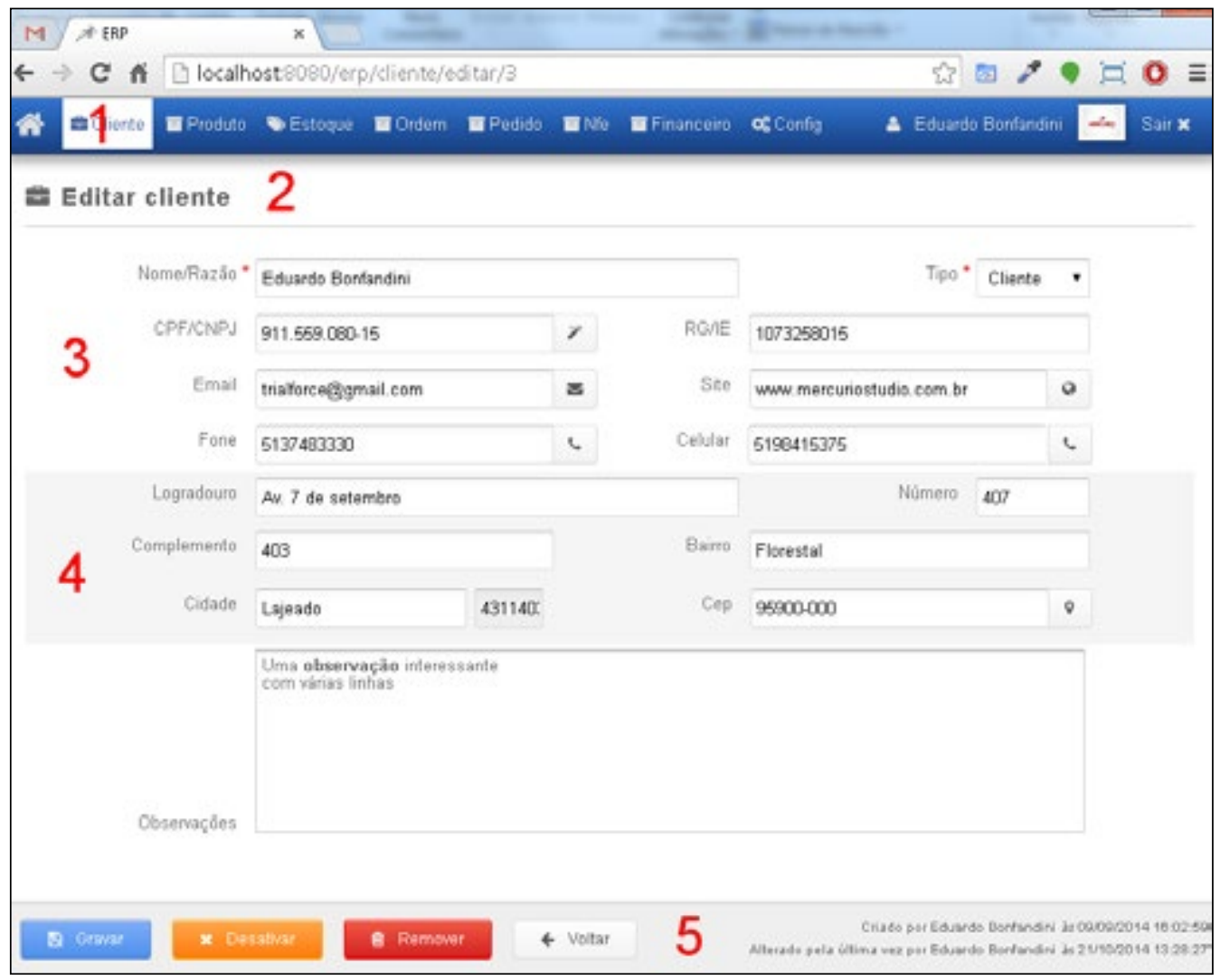

Fonte: do autor.

\section{PROCEDIMENTOS METODOLÓGICOS}

$\mathrm{O}$ presente trabalho teve o caráter interdisciplinar, pois objetivou integrar conceitos tecnológicos da área de computação com o contexto social, buscando qualificar o processo de consultas, retiradas e reservas de materiais bibliográficos da comunidade acadêmica de uma Instituição de Ensino Superior.

A proposta de reformulação do sistema de biblioteca foi direcionado ao atual sistema da instituição Centro Universitário UNIVATES e dividiu-se nas seguintes fases:

- Levantamento bibliográfico acerca das boas práticas de IHC.

- Projeto de uma nova interface para interação dos usuários.

- Desenvolvimento de uma nova versão do sistema de consultas, reservas e retiradas. 
- Validação da nova proposta junto à comunidade acadêmica, realizado por meio de amostragem.

O desenvolvimento da nova versão ocorreu em um ambiente à parte da instituição Univates. Tecnologias como: linguagem de programação PHP, CSS, HTML, JavaScript e banco de dados PostgreSQL foram utilizadas no processo de implementação. Um servidor executando a nova versão esteve disponível para acesso via internet durante um período de 20 dias.

Os materiais disponíveis no ambiente de validação correspondiam a um pequeno subconjunto de materiais da real biblioteca. Dessa forma, os usuários participantes do período de testes poderiam digitar nomes de obras de diferentes áreas do conhecimento, verificar detalhes como autor, ano, editora, dentre outras informações.

$\mathrm{O}$ processo de teste representou um componente extra do desenvolvimento do projeto e não será especificado nesse documento. Cada usuário que acessava o novo portal da biblioteca, preenchia um breve questionário de caracterização do perfil do usuário e era então conduzido de maneira automática para o novo layout de navegação, sendo orientado por mensagens no topo da tela sobre as tarefas que deveria realizar. Ao todo, um conjunto de 9 tarefas foram solicitadas. Ao completar a tarefa corrente, a tarefa seguinte era oferecida. Ao final, um breve questionário composto por quatro questões sobre a atividade era apresentado.

A fase de testes caracterizou-se como fundamental para verificação da proposta. Para isso, entendeu-se que quanto maior o número de usuários participantes, maior credibilidade e diversidade de perfis participariam. Para tanto, um e-mail convidando para participação da avaliação do novo sistema foi disparado para listas de alguns cursos da instituição. Ao total, 150 pessoas realizaram as tarefas, porém somente 116 responderam aos questionários pré e pós teste.

\section{DESENVOLVIMENTO DA PROPOSTA}

Fazendo uso dos conceitos de IHC abordados no Capítulo 2, serão apresentadas a seguir algumas telas do novo sistema proposto para a biblioteca Univates. Primeiramente são apresentadas telas do sistema atual apenas para referência e demonstração. Não foi objetivo do presente trabalho apontar problemas ou comparar cada recurso implementado com o sistema atual.

A Figura 3 apresenta a interface atual do sistema de biblioteca da Univates, Gnuteca. A parte superior (1) apresenta o logo do aplicativo e opção de autenticação. Logo ao lado esquerdo, como primeira ação do usuário é apresentado o menu da minha biblioteca (2). Ao lado do menu minha biblioteca é apresentado a área de pesquisa (3). 
Figura 3 - Tela do sistema de biblioteca em vigor

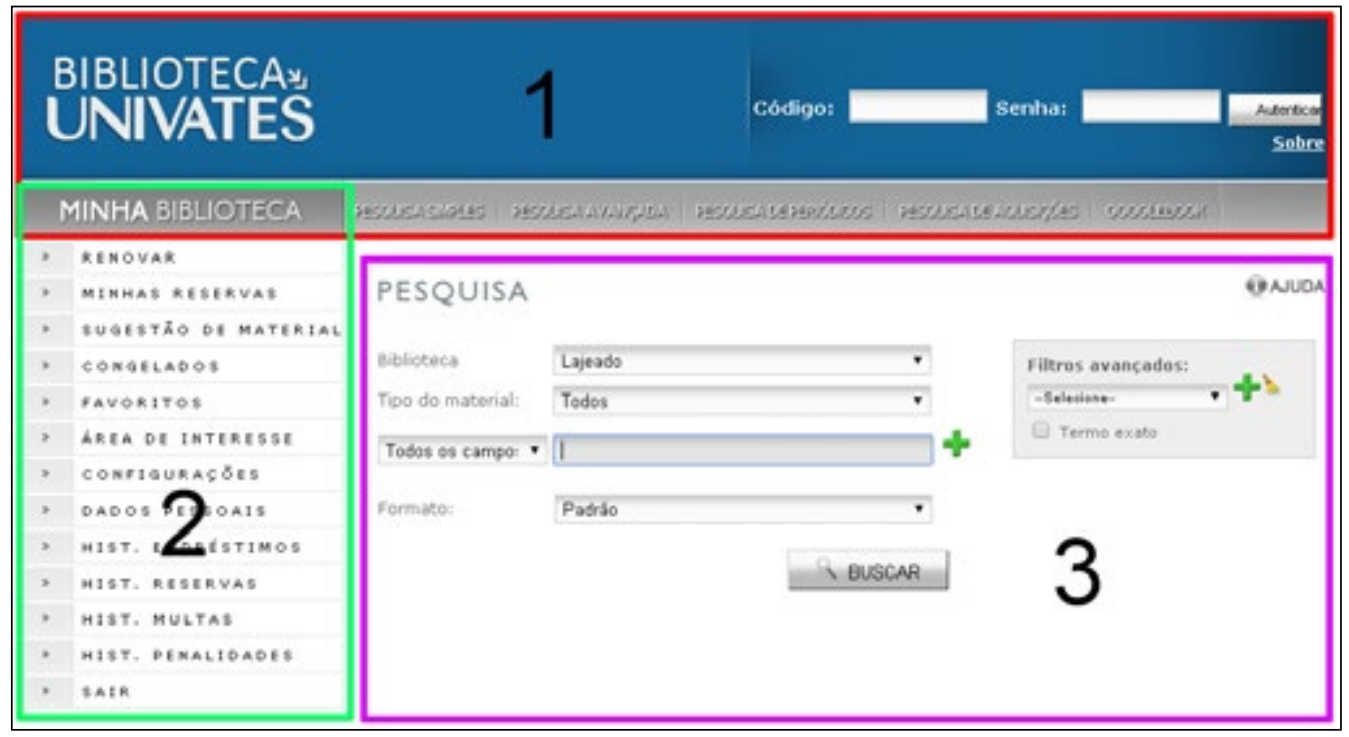

Fonte: Disponível em: <www.univates.br/gnuteca>. Acesso em: 08 out. 2014

Importante salientar que alguns recursos foram deixados de fora da implementação. Funções como renovações, financeiro, congelamento de exemplares, dentre tantas outras, foram suprimidas do modelo proposto.

A sequência de Figuras de 4 a 8 apresentam as principais telas desenvolvidos. Por meio delas, é busca-se demonstrar o novo formato de interação proposto. $\mathrm{O}$ sistema passou ter a aparência de uma página de internet, com fácil navegação, um agrupamento de dados diferenciada, uma nova apresentação dos resultados de busca e detalhes, além de flexibilizar a interação, permitindo cliques em áreas como capa da obra, título e área de fundo da listagem. 
Figura 4 - Tela de busca simples

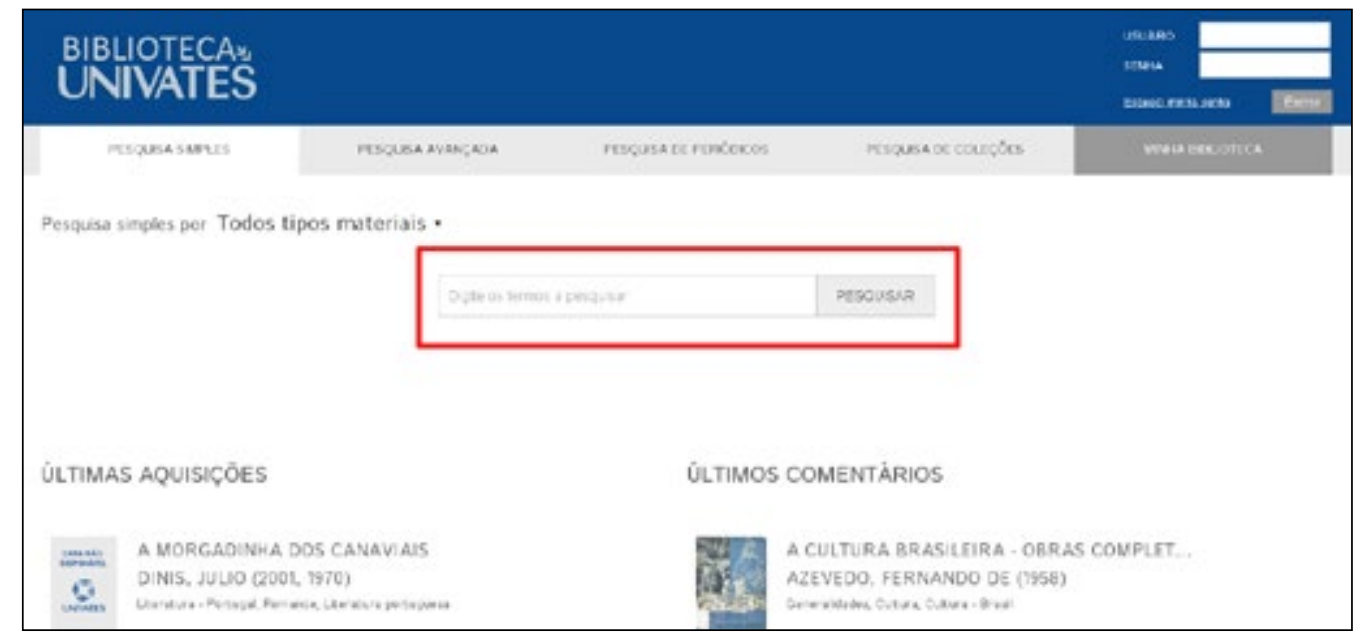

Fonte: do autor.

Figura 5 - Resultados de uma busca

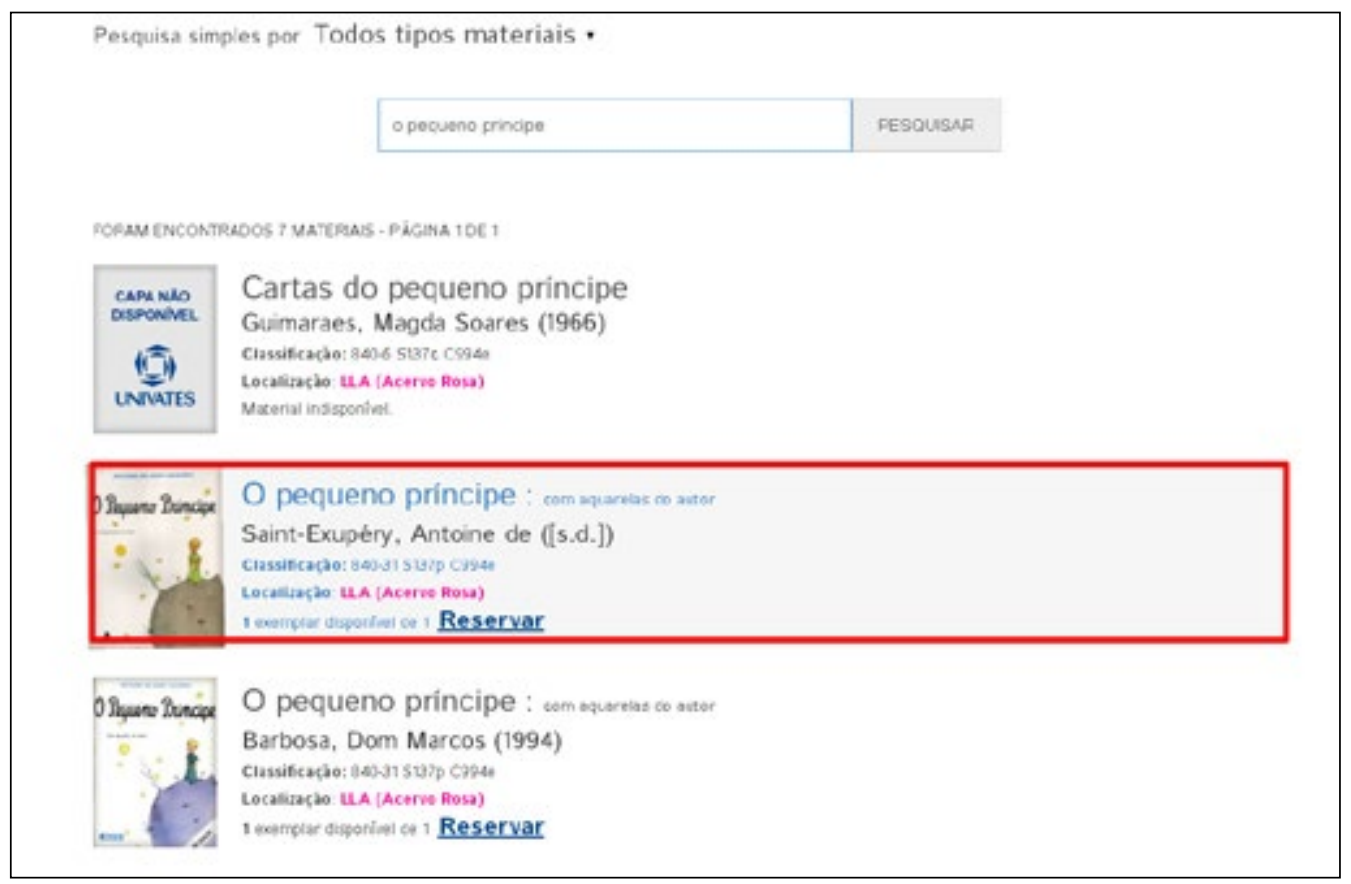

Fonte: do autor. 
Figura 6 - Detalhes de uma obra

\section{BIBLIOTECA UNIVATES}

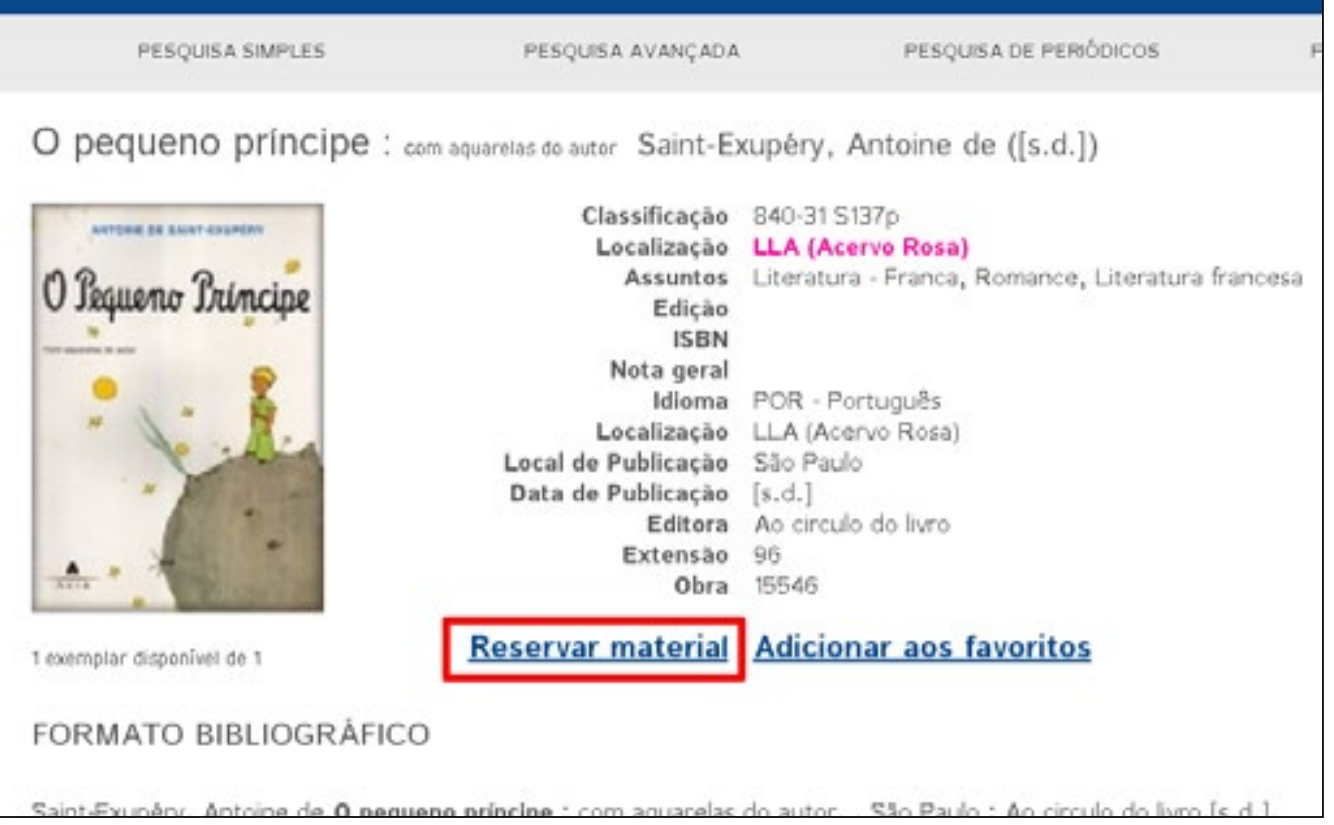

Fonte: do autor.

\section{Figura 7 - Busca avançada}

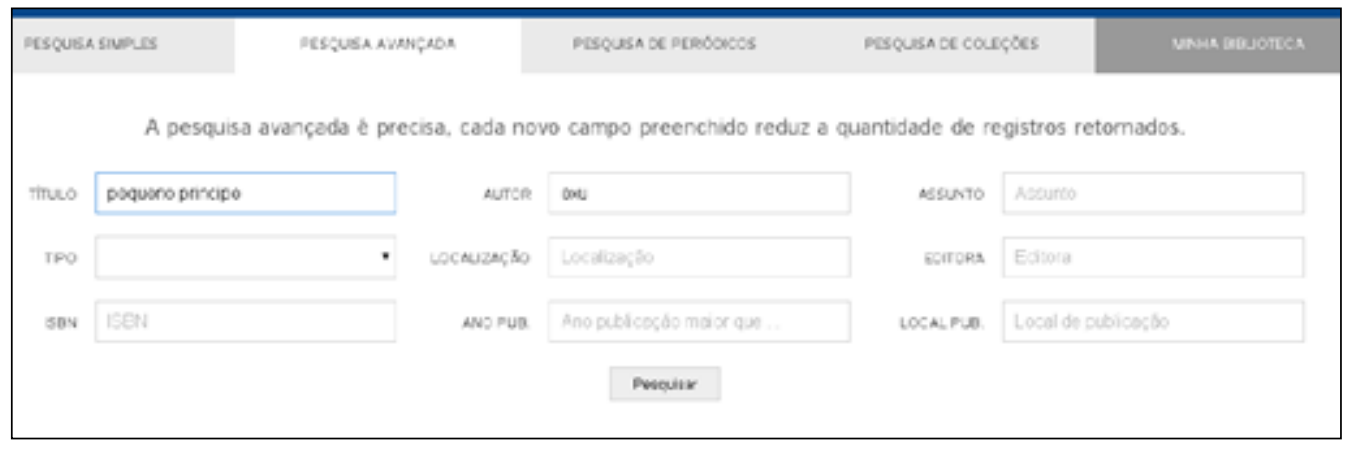

Fonte: do autor. 
Figura 8 - Tela de reservas

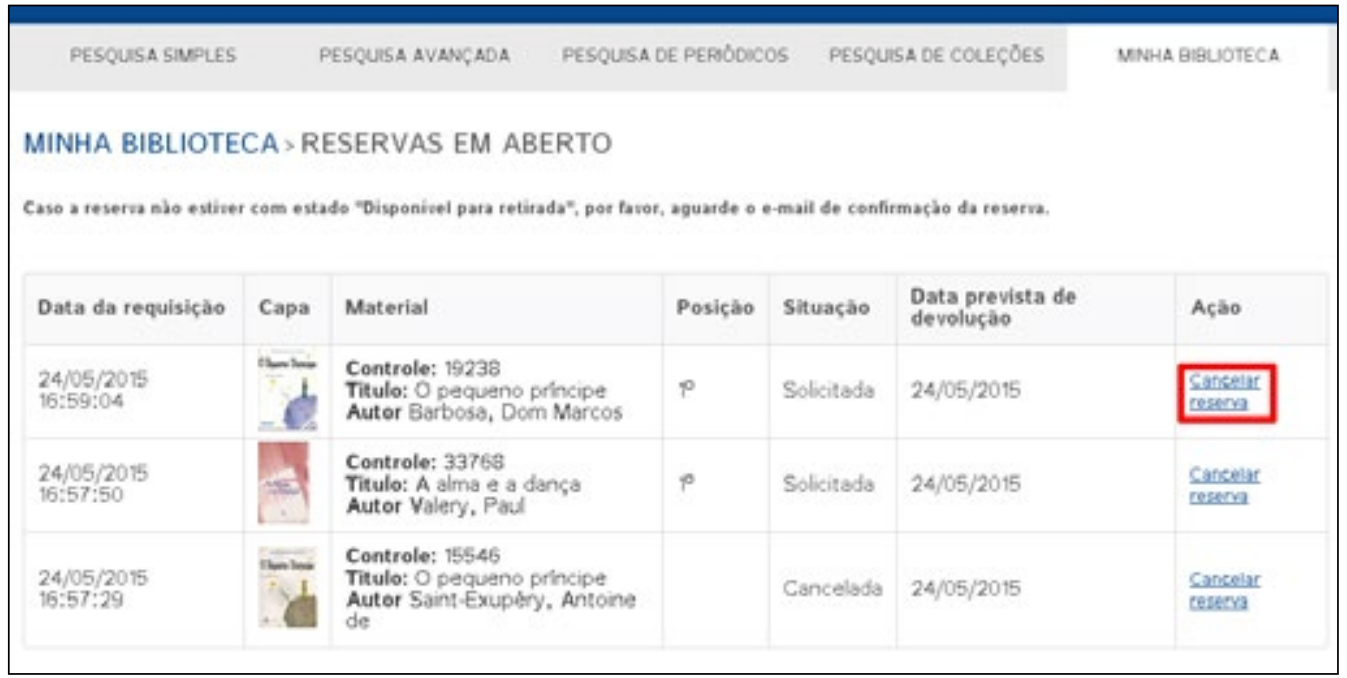

Fonte: do autor.

A Tabela 2 apresenta as 9 tarefas desempenhadas pelos participantes dos testes.

Tabela 2 - Lista de tarefas do teste de usabilidade

\begin{tabular}{c|l}
\hline $\mathbf{N}^{\mathbf{o}}$ Tarefa & \multicolumn{1}{c}{ Descrição } \\
\hline 1 & $\begin{array}{l}\text { Pesquisar qualquer material (livro) na pesquisa simples. Exemplo: “O } \\
\text { pequeno Príncipe }\end{array}$ \\
\hline 2 & Ver mais informações sobre o livro \\
\hline 3 & Fazer login/entrar no sistema. Exemplo: usuário: teste senha: 123 \\
\hline 4 & Reservar qualquer livro \\
\hline 5 & $\begin{array}{l}\text { Encontrar livros em uma pesquisa avançada utilizando mais de um } \\
\text { parâmetro }\end{array}$ \\
\hline 6 & Registrar um comentário/avaliação para um livro \\
\hline 7 & $\begin{array}{l}\text { Executar uma nova busca, ver mais informações sobre um livro, entrar } \\
\text { em um livro relacionado a ele }\end{array}$ \\
\hline 8 & Adicionar qualquer material aos favoritos \\
\hline 9 & Cancelar uma reserva na Minha Biblioteca \\
\hline
\end{tabular}

Fonte: do autor.

A Figura 9 apresenta a tela inicial dos testes, após preenchimento do questionário pré-teste. No topo é possível visualizar uma tarja verde onde ficam as mensagens do sistema automático de tarefas. Conforme uma tarefa 
fosse completada, a próxima era automaticamente exibida. A opção de pular também estava disponível para o caso do usuário testador não conseguir desempenhar a atividade.

Figura 9 - Navegação durante os testes

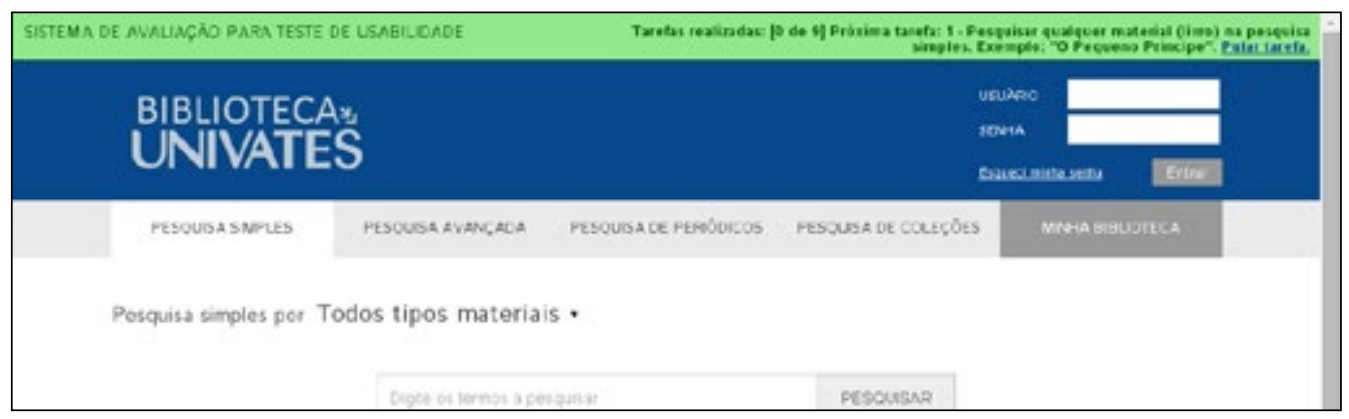

Fonte: do autor.

Realizados os testes, analisou-se os dados. Para cada evento realizado pelo usuário na nova interface, foi gerado um registro contendo data, hora e local de sua interação (clique). Essa ação objetivou monitorar se as funcionalidades implementadas foram perceptíveis aos usuários, provocando maior nível de usabilidade.

Em uma escala de 1 a 5 , sendo 5 muito satisfeito, os usuários classificaram a satisfação e a dificuldade conforme a Tabela 3.

Tabela 3 - Resultado geral da avaliação pós-teste

\begin{tabular}{ll}
\hline Item & Valor \\
\hline Satisfação & 4,20 \\
Dificuldade & 1,33 \\
\hline
\end{tabular}

Fonte: do autor.

\section{CONSIDERAÇÕES FINAIS}

Após aplicação da metodologia e execução de cada uma das etapas do processo foi concluído que o projeto de uma nova proposta de usabilidade para o aplicativo web de biblioteca da Univates, realmente alcançou os objetivos estabelecidos. Devido a baixos tempos de resoluções de testes, altos índices de aceitação e baixo grau de dificuldade reportada pelos usuários, concluiuse que ele se tornou mais usável que a ferramenta atualmente utilizada pela instituição. 
Diversos comentários descritivos foram fornecidos pelos usuários na questão aberta do questionário pós-teste, muitos deles apresentaram mensagens muitos positivas, que foram dadas de espontâneo pelos usuários. Por outro lado, a maioria dos usuários que reportaram algum desconforto em relação ao sistema foi por realmente acreditarem ser um sistema finalizado, por exemplo, quando relatam não encontrar livros que sabiam que existiam na biblioteca. Entretanto isso deixa claro que alguns usuários não leram com atenção as etapas iniciais que elucidavam sobre o passo a passo dos testes, o que resultou na incompreensão do objetivo principal da tarefa, situação que não ocorreu nos testes presenciais.

Quanto aos usuários em si, foi notado que os experientes são bastante exigentes, realmente, críticos. A característica que se tornou mais clara foi a importância do uso do conhecimento prévio que o usuário possui, ou seja, de nada adianta uma interface moderna e intuitiva se o usuário não conhece a sua forma de trabalhar.

Também foi observado que usuários distintos, mesmo se enquadrando em um mesmo perfil, pensam de maneiras muito distintas, sendo quase impossível agradar a todos os gostos.

Os testes de usabilidade, sendo presenciais ou remotos, sendo individuais ou em grupos auxiliam bastante a compreensão do que o usuário precisa para realizar suas tarefas.

A usabilidade realmente é um recurso importante, e atualmente pode-se dizer vital. Os desenvolvedores que realmente desejaram satisfazer os seus usuários precisam dar atenção à usabilidade, antes que os usuários os abandonem, ou seja, a usabilidade é um fator decisivo para o sucesso e aceitação de uma aplicação, seja web, desktop ou móvel. Os seus princípios e instruções são simples, claros e de resultados óbvios, basta dedicação por parte das equipes para implantá-los.

\section{REFERÊNCIAS}

CYBIS, Walter; BETIOL, Adriana Holtz; FAUST, Richard. Ergonomia e usabilidade: conhecimentos, métodos e aplicações. 2. ed. rev. ampl. São Paulo: Novatec, 2010.

ENGHOLM JÚNIOR, Hélio. Engenharia de software na prática. São Paulo: Novatec, 2010.

FOWLER, Susan; STANWICK, Victor. Web application Design Handbook: best practices for Web-Based Software. Estados Unidos: 2004. Disponível em: $<$ http:/ /www.amazon.com/Web-Application-Design-Handbook-Technologies/ dp/1558607528>. Acesso em: 17 ago. 2014.

GABRIEL, Martha. SEM e SEO - Dominando o marketing de busca. Novatec Editora, 2009. 
GOMES, Carolina Glayce. Avaliação da usabilidade do sistema pergamum e gerenciamento de bibliotecas.[s. ed.]." Arcos:[sd].

KRUG, Singer; BLACK, Roger. Não me faça pensar!: uma abordagem de bom senso à usabilidade na web. Rio de Janeiro: Alta Books, 2013.

NIELSEN, Jakob, Usability Engineering, Elsevier, 1994.

NIELSEN, Jakob; LORANGER, Hoa. Usabilidade na web. Rio de Janeiro: Elsevier, 2007.

PRESSMAN, Roger S. Engenharia de software: uma abordagem profissional. 7. ed. Porto Alegre: AMGH, 2011.

SOMMERVILLE, Ian. Engenharia de software. 9. ed. São Paulo: Pearson Prentice Hall, 2012. 